\section{Rates of creatinine and urea clearance in preterm infants on the 3rd day after birth}

Sir,

In a recent paper published in the Archives (Sertel and Scopes, 1973), we reported the results of creatinine clearances in normal term infants. I have now studied rates of creatinine clearance in male preterm infants on the 3rd day of life. In the same infants the rates of urea clearance were measured.

There were 11 male preterm infants studied on the 3rd day of life. Gestational age varied from 32 to 35 weeks, birthweight from $2.0 \mathrm{~kg}$ to $2.62 \mathrm{~kg}$. All infants were bottle fed using a cow's milk formula $(120 \mathrm{ml} / \mathrm{kg}$ per day). The procedure for collection of urine and capillary blood and for the determination of plasma and urine creatinine was the same as described in the previous paper. Plasma urea concentration was measured by the Barthelot reaction (Fawcett and Scott, 1960), and urine urea concentration by autoanalyser (Marsh, Fingerhut, and Kirsch, 1957). The summarized findings are presented in the Table. The creatinine clearance ranged from 10.6 to $23.1 \mathrm{ml} / \mathrm{min}$ per $1.73 \mathrm{~m}^{2}$, with a mean of $16.4 \mathrm{ml} / \mathrm{min}$ per $1.73 \mathrm{~m}^{2}$. The urea clearances ranged from 4.5 to $22.5 \mathrm{ml} / \mathrm{min}$ per $1.73 \mathrm{~m}^{2}$, with a mean of $11.4 \mathrm{ml} / \mathrm{min}$ per $1.73 \mathrm{~m}^{2}$. No correlation was found between gestational age and the creatinine or urea clearances in this study.

Comparing the results with the rates of creatinine clearance of term infants found in our previous study, it appears that those of preterm infants are consistently lower. Plasma creatinine concentration in preterm infants measured on the 3rd day of life is lower than the level seen in term infants on day 1 , but higher than that of term infants on day 6 . Preterm infants have lower urinary creatinine concentrations than term infants on either day 1 or day 6.

The values for urea clearance and plasma urea concentration on preterm infants are slightly lower than those of Dean and McCance (1947) in their study on term infants with meningomyelocele. They are also slightly lower than the values obtained by Gordon, Harrison, and McNamara (1942), but the infants in the latter series were all over one week of age. However, no distinction was made between small-for-dates and preterm infants in this latter study. The same criticism can be levelled against the 6 premature infants studied by Barnett et al. (1948).

Thus the rates of creatinine and urea clearance in 11 normal preterm infants of less than 1 week of age were found to be even lower than those of normal term infants. The implications of these very low levels of rates of clearance are discussed in the previous paper.

\section{HÜSEYIN SERTEL \\ Institute of Child Health, Hammersmith Hospital,} London W.12.

\section{REFERENCES}

Barnett, H. L., Hare, K., McNamara, H., and Hare, R. (1948). Measurement of glomerular filtration rate in premature infants. fournal of Clinical Investigation, 27, 691.

Dean, R. F. A., and McCance, R. A. (1947). Inulin, diodene, creatinine and urea clearances in newborn infants. Fournal of Physiology, 106, 431.

Fawcett, J. K., and Scott, J. E. (1960). A rapid and precise method for the determination of urea. Fournal of Clinical Pathology, 13, 156.

Gordon, H. H., Harrison, H. E., and McNamara, H. (1942). The urea clearance of young premature and full term infants. Fournal of Clinical Investigation, 21, 499.

TABLE

Urea and creatinine clearance in preterm male infants on the 3rd day of life

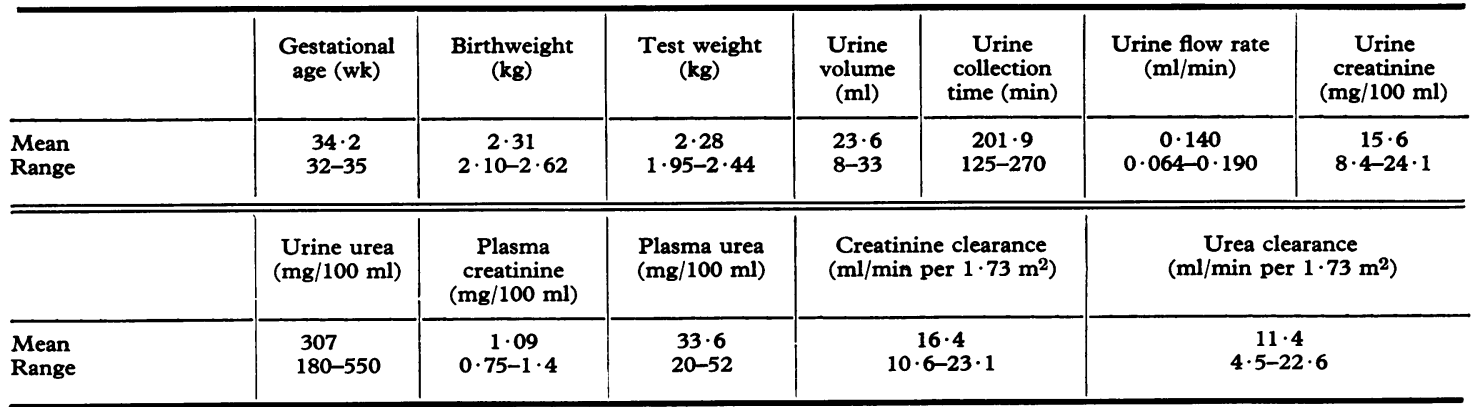


Marsh, W. H., Fingerhut, B., and Kirsch, E. (1957). Determination of urea nitrogen with the diacetyl method and an automatic dialyzing apparatus. American fournal of Clinical Pathology, 28, 681 .

Sertel, H., and Scopes, J. W. (1973). Rates of creatinine clearance in babies less than one week of age. Archives of Disease in Childhood, 48, 717 .

\section{Solubilization}

Sir,

Solubilization might be a useful new word if used to mean the process of making soluble or more soluble. Glasgow, Hamilton, and Sass-Kortsak (1973) do not define the term but use it as though they mean solubility or possibly sometimes solution. How did they measure '\% lipid solubilized' (Fig. 2)? Will the authors kindly say what they mean?

P. R. EVANS

The Hospital for Sick Children, Great Ormond Street London WC1N $3 J H$.

REFERENCE

Glasgow, J. F. T., Hamilton, J. R., and Sass-Kortsak, A. (1973) Fat absorption in congenital obstructive liver disease. Archives of Disease in Childhood, 48, 601 .

We showed Dr. Evans's letter to Dr. Glasgow, who replied:

We are grateful to Dr. P. R. Evans for the opportunity of clarifying our use of the term 'solubilization'.

Much of the fat resulting from the hydrolysis of dietary lipid is itself insoluble in water. Bile salts form micelles with these insoluble lipids thereby rendering them water soluble. It is this process of rendering insoluble hydrolysed fat soluble in water which we have termed 'solubilization of lipid'.

In our studies small bowel contents aspirated after a fatty meal were separated by means of ultracentrifugation into a supernatant (lipid) phase and a clear infranatant (aqueous) phase. The fat in the aqueous phase represents the fat which has been rendered soluble in water, i.e. solubilized.

In our article, 'Fat absorption in congenital obstructive liver disease', we compared the concentration of fat in the aqueous phase (solubilized fat) with that in the aspirated juice as a whole (i.e. total lipid) and used this as an indication of the degree to which lipid had been solubilized. The '\% lipid solubilized' is therefore the concentration of fat in the aqueous phase compared to that in the juice as a whole related to 100 .

J. F. T. GLASGOW Department of Child Health, Institute of Clinical Science, Grosvenor Road, Belfast BT12 $6 B J$.

\section{Fingerprints in childhood coeliac? disease}

Sir,

The association of fingerprint ridge atrophy with intestinal villous atrophy in coeliac patients was first 흠 reported by David, Ajdukiewicz, and Read in 1970; $\frac{\bar{\omega}}{\partial}$ according to these authors, changes in fingerprints were $\mathbb{\Phi}$ found in most of adult coeliac patients and in the few untreated children they studied. Others have questioned os these findings both in adults, and more particularly, in $\vec{\circ}$ children (McCrae et al., 1971; Mylotte et al., 1972).

13 coeliac children with ages ranging from 2 to $16 \vec{\omega}$ years were submitted to intestinal biopsy. These children 0 were divided into two groups, according to whether previously diagnosed (Group I, 9 children) or newly? diagnosed (Group II, 4 children) as coeliacs. In Group I, 6 children were on an unrestricted diet and the biopsy in all except one showed subtotal villous atrophy, the only $\vec{c}$ exception showing a partial villous atrophy. 1 child was 0 on a low gluten but not strictly gluten-free diet and had a partial villous atrophy. 2 other children were on a strict $\vec{c}$ gluten-free diet and had normal intestinal mucosa. In Group II, all 4 children had a flat mucosa with subtotal villous atrophy.

Fingerprints were obtained in each patient from the thumb, middle, and little fingers of the right hand. For $\vec{b}$ each print in a coeliac child prints were obtained from $2 \neq$ control children of the same age. Particular care was put in taking the print of the little finger, the most frequently affected in coeliac patients according to David et al. (1970). In taking the prints, the fingertips were first $\overline{0}$ cleaned with ether, blotted with a lead pencil, and the print obtained on transparent sellotape which in turn was stuck on a white cardboard.

Normal fingerprints were obtained from all coeliac children, which is in agreement with the findings of McCrae et al. (1971), Mylotte et al. (1972), and David, Ajdukiewicz, and Read (1973).

We conclude that fingerprinting is of no diagnostic value in childhood coeliac disease.

J. SALAZAR DE SOUSA and J. PASCOAL DUARTE Department of Paediatrics, University of Lisbon and Hospital de Santa Maria, 으 Lisbon, Portugal.

\section{REFERENCES}

David, T. J., Ajdukiewicz, A. B., and Read, A. E. (1970). Finger- N print changes in coeliac disease. British Medical fournal, 4, 594.

David, T. J., Ajdukiewicz, A. B., and Read, A. E. (1973). Dermal N and epidermal ridge atrophy in celiac sprue. Gastroenterology, 64, 539.

McCrae, W. M., Sandor, G., Sangani, A. P., and Stalker, R. (1971). Fingerprint changes in coeliac disease. British Medical fournal, 3, 109.

Mylotte, M., Egan-Mitchell, B., Fottrell, P. F., McNicholl, B., and McCarthy, C. F. (1972). Fingerprints in patients with coeliac disease and their relatives. British Medical fournal, 4, 144. 